a Irajor purpuse or tre i ecrimcal Information Center is to provide the broadest dissemination possible of information contained in DOE's Research and Development Reports to businese industry, the academic community, and federal, staie and local governments.

Although a small portion of this report is not reproducible, it is being made available to expedite the availability of information on the research discussed herein. 
The FEL electron linac consists of three buncher cavities: two accelerator cavities and a deflection cavity, each with its own phase-coherent rf source. All sources will ba fulsed for 100 us at a l-pps rate. The phase and amplitude stability requirements are $\pm 1 / 2^{\circ}$, and $\pm i / 2 \%$. There are two subharmonic buncners, each requiring $5 \mathrm{~kW}$ at $108.33 \mathrm{MHz}$. All remaining cavities operate at $1300 \mathrm{MHz}$. The fundamental buncher requires $5 \mathrm{~kW}$, whereas each of the accelerating casities requires at least $3 \mathrm{MW}$. The deflection cavity requires up to $100 \mathrm{~kW}$, which is zoupled from one of the accelerator cavity if sources. Prominent features of the $r^{f}$ system are the phase and amplitude control circuits and the multimegawatt klystron amplifiers. Three 13707 klystrons were obtained from the AM?AD radar site at White Sands, which was decommissioned in the early 1970s. The tubes originally were designed to produce 10-MW, 10-us pulses. Each tube has delivered over 3.6-MW, i00-us pulses in the FEL system.

\section{Accelerator Descr}

The Los Alamos FFL uses the output of a specialized electron linac to produce high-energy-light pulses in the far infrared region.

The following description of the linac, used in the FEL oscillator experiment, will clarify the functions of each of the rf systems and will lead to an unierstanding of the ingredients that dictate the rf systems' requirements.

The linac cutput beam conslsts of a train of micropulses, $100-\mathrm{A}$ peak, $30 \mathrm{ps} w$ de and $246 \mathrm{~ns}$ apart. The train, q100 us long, occurs once every second.

The linac is composed of an $80-k V$ injector, followed by three bunchers then two accelerator sertions. Find beam eneriy is? MeV. The accelerator sections are sise-couried-cavity struccur $\therefore$ and a e operated at $1.3 \mathrm{GH}$, which is the inde's fundamental frepuency.

Tile hearn is modulated within the injector at onesixtieth of the fundamental frequency, or ?1.67 Mlly. The periol of this frequenry determines the spacing of the micropulses. The modulated injector sutput brar Dasses through twu subharmonic hunchers that are operated dt one-twelfth of the fundanental frequency, or 1011.33 MIIz. These bunchers servo lo squecie the width of the beam-inodulation pulses lown to 360 ps. These bunchers are followed by a fundanental buncher and then the two accelerating cavities. Final siues ind of the micropulse widtis to 30 ps occurs in these fundamental-f requem:y struciures.

There is, In addition to the linac, a 1.3-Chll def lection cavity that is used for electron beam dialy. nostics following energy exchange to the laser.

line if Rejulrement:

Table I presents the major repulrement; of roch if power system for the fF. Project. Farh system oht ails lls excitation from a master nsclllator that produces coliesent stgmals at. $71.6 / \mathrm{MHz}$, 10H. $11 \mathrm{MHz}$.

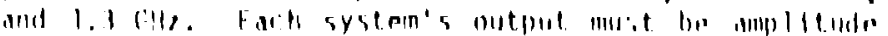

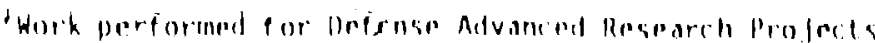

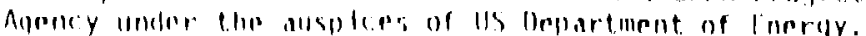

TABLE i

\section{FREE ELECTRON LASER RF REQUIREMENTS}

Subharmonic buricher sources (2)

Frequency

Power (peak)

Fundamental buncher source (1)

Frequency

Power (peak)

Accelerating cavity sources (2)

Frequency

Power (peak)

Deflection cavity source (1)

Frequency

Power (peak)

$108.33 \mathrm{MHz}$

$5 \mathrm{~kW}$

$1300 \mathrm{MHz}$

$5 \mathrm{~kW}$

$1300 \mathrm{MHz}$

3. $2 \mathrm{MW}$

$1300 \mathrm{MHz}$

$100 \mathrm{kw}$

and phase stable within $\pm 1 / 2 \%$ and $\pm 1,2^{\circ}$ respectively. The powers listed are peak powers: th. rf pulse duration is $100 \mu \mathrm{s}$, occurring at a l-pps ate.

\section{The rf Power Sources}

Figure 1 is a block diagram of the FEL rf power sources. Each of the two accelerator cavitles is powered by a Litton L 3707 klystron.

Power for each of the bunchers as well as the klystron drive is provided by iadividual $5-\mathrm{kW}$ linear amplifiers. These amplifiers require an $7.14-d B m$ input level to produre $5-\mathrm{kW}$ output. The amplifiers are made up of a solid-state rilass $A$ amplifier followed by several triode stayes in cascade. The triodes are operated Class B. Power for the deflection cavity is coupled from the waveguide qoing to the first accelerator.

Flgure 2 shows the detalls of the deflectioncavity power-coupling scheme. Power in llybrid 1. Port $A$ is split equally between Ports $C$ and $D$, with port $C$ lagqing by $90^{\circ}$. The power into Hybrid? Port $A$ is split in similar fashion. Adjustable shorts are connected to Ports $C$ and [] of both Hybrids 2 and a. If the distarces from $C$ and 0 to the shorts are equal. the reflectlons from those shorts will be combland in Port $B$ only: therefore. Hybrids? and 4, with their assoctated adiustable shorts, function simply

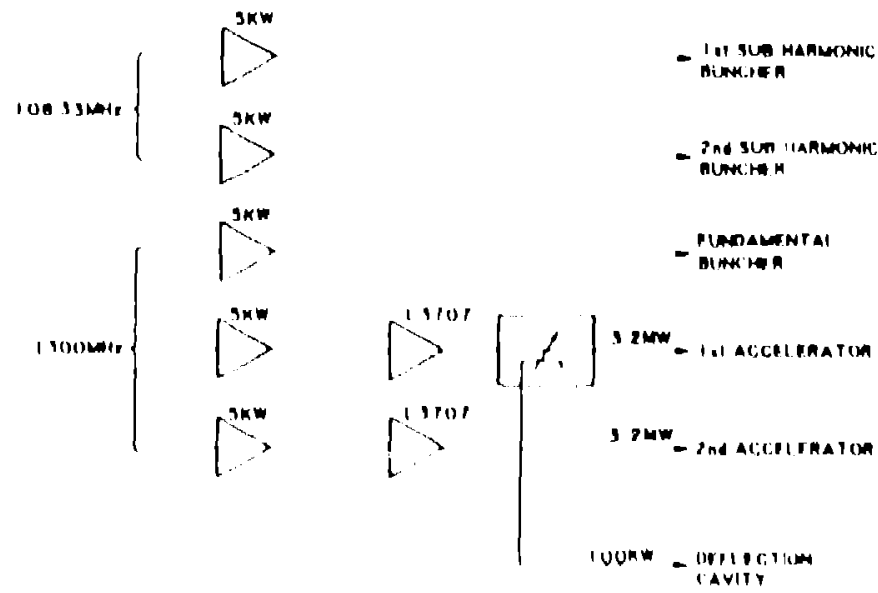

11]. 1. If. I powpr sources. 
sugmitied to 1983 Particle Accelerator Conference,

March 21-23, Santa Fe, NM

\section{IDSC 'I.AIMER}

This repurl was prepured as an accumm of work spons'ored by un ugency of the linited States (iovermment. Neither the IJnited Silutes (iovernment nor nny agency thereof, mor any of their cmployecs, makes uny wurrmuly, express or implied, or ussumes uny legal liability or responsibility for the uceurncy. completeness, or usefulness of ony informution, uppuratur, product, or I iness discloned, of repesesents that its use would now infringe privitely owned rights. Refer-

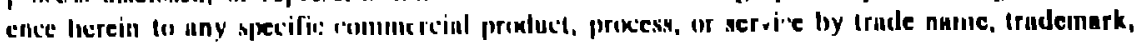
, 1 unfucturer, or otherwise docs not necessurily constifute or imply its endorsemont, recom-

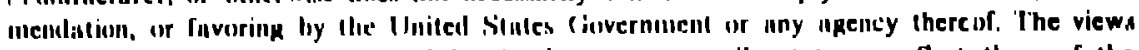
and opinions of authom cxpressed lecrein du mot necessurily :ilule or reflect tluns of the

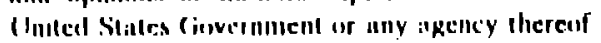

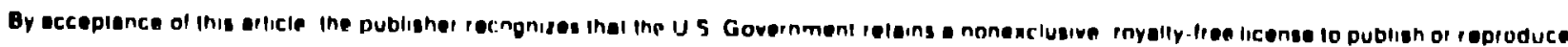

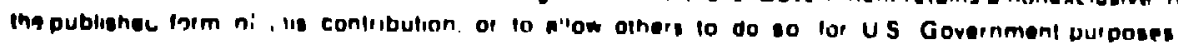

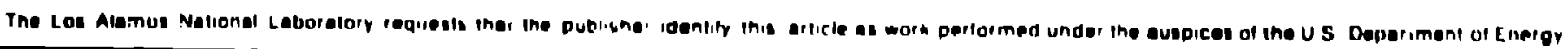

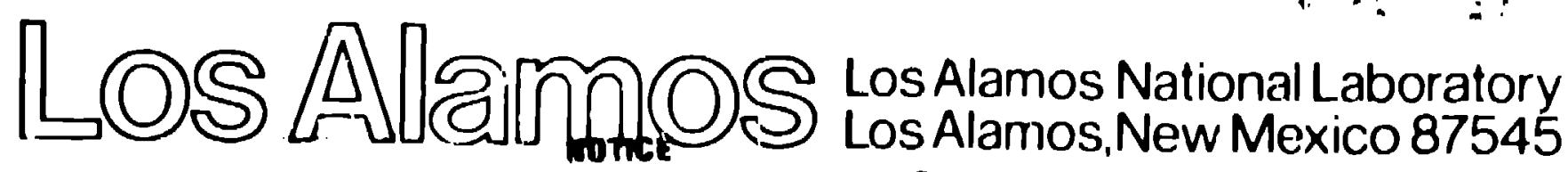

com no an a PAnTIOAS of TMIS MEPOAT AAE ILLERIALE.

aim ine 
Carl C. Friedricis, Paul J. Tallerico and N1lliam J. Hoffert, AT-5, MS H827 Los Alames National Laboratory, Los Alamos, NM 87545

\section{Summary}

The FEL eiectron linac consists of three buncher cavities: two accelerator cavities and a deflection cavity, each with its own phase-coherent $r f$ source. All sources will be pulsed for $100 \mu \mathrm{s}$ at a l-pps rate. The phase and amplitude stability requirements are $\pm 1 / 2^{\circ}$, and $\pm i / 2 \%$. There are two subharmonic bunchers, each requiling $5 \mathrm{~kW}$ at $108.33 \mathrm{MHz}$. A 11 remaining cavities operate at $1300 \mathrm{MHz}$. The fundamental buncher requires $5 \mathrm{~kW}$. whereas each of the acceleratiris cavities requires at least $3 \mathrm{MW}$. The deflection cavity requires up to $100 \mathrm{~kW}$. which is coupled from one of the accelerator cavity $r f$ jources. Frominent features of the rf system are the phase and amplitude control circuits and the multimegawatt klystron amplifiers. Three $L 3707$ klystrons were obtained from the AMRAD radar site at white Sands, which was decommisstoned in the early 1970s. The tubes orlgtrially were designed to produce 10-MW, 10-us pulses. Fach tube has delivered over 3.6-MW, 100-us pulses in the FEL system.

\section{Accelerator Description}

The Los Alamos FEL uses the nutput of a specialized electron linac to produce high-energv-light pulses in the far infrared regiun.

The following description of the linac, used in the FEL oscillator experiment, wlll clarify the func tions of each of the rf systems and will lead to an understanding ol the inqrediencs that dictate the $r f$ systeris' requitrements.

The linac cutput $t: a m$ consists of a train of micropulses, $100-\mathrm{A}$ peak, $30 \mathrm{ps}$ wide and $246 \mathrm{~ns}$ apart. The tratn, 2100 is long, occurs once every second.

The linac is composed of an $80-k V$ injector, followed by three bunchers then two accelerator sertions. Final heam energy is ? I MeV. The accelerator sections are side-coupled-cavity structures and are oparated at $1.3 \mathrm{FHz}$, which is the linac's fundamental frequency.

The hearn is modulated within the injector at onesixtieth of the fundamental fremuency, or 21.67 Mliz. The pertad of this frequency deterinines the spacing of the micropulses. The modulated infector output heam basses through two subharmonic bunchers that are operated at one-twelfth of the fundamental frequency, or 108.33 Mllz. These bunchers serve to soveeze tha willh of the beam-inodulation pulses down to $360 \mathrm{ps}$. These bunchers are followeri hy fundamental buncher and then the two accolerating cavitles. Final squeezing of the intcropulse width to 30 ps occurs in these fundamental-i requency structures.

There is, in addition to the linac, a 1.3-Gillz deflectlon cavity that 19 used fowelectron beam diagnostics following energy exchange to the laser.

\section{The rf Rerutrements}

lable I presents the mator reuul rements of each if nower system for the Ffl. Profect. I aci. system ohtains 1ts excitation from a master osclllator thi.t.

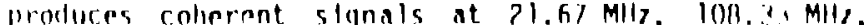
and 1.1 Glly. Fach system's output must be amplitude

Work performed for hepense Molvanced Resoarch Projects

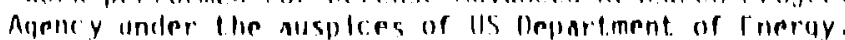

TABLE I

FREE ELECTRON LASER RF REQUIREMENTS

Subharmonic buncher srurces (2)

Frequercy

Power (peak)

Fundamental huncher source (1)

Frequency

Power (peak)

Accelerating cavity sources (2)

Frequency

Power (peak)

Deflection cavity sorrce (1)

Frequency

Power (peak)
$108.33 \mathrm{MHz}$

$5 \mathrm{~kW}$

$1300 \mathrm{MHz}$

$5 \mathrm{~kW}$

$1300 \mathrm{MHz}$

$3.2 \mathrm{MW}$

$1300 \mathrm{MHz}$

$100 \mathrm{~kW}$ and phase stable within $\pm 1 / 2 \%$ and $\pm 1 / 2^{\circ}$ respectively. The powers 1 isted are peak powers: the rf pulse duration is $100 \mu \mathrm{s}$, occurring at a l-pps rate.

\section{ihe ri Power Sources}

Figure 1 is a block diagram of the FEL rf power sources. Each of the two accelerator cavities is powered by a Litton L 3707 klystron.

Power for each of the bunchers as well as the klystron drive is provided by individual 5-kw linear amplifiers. These amplifiers require an vi4-dBin input level to prodice $5-\mathrm{k} 4$ output. Tre amplifiers are made up of a solid-state Class A implifier folluwed by several triode stages in cascade. Tr.e triodes arc operated Class $B$. Power for the deflection cavity is couplet from the waveguide going to the first accelerator.

Flyure ? shows the detalls of the deflectioncavity power-coupling scheme. Power in Hybrid I, Port $A$ is split equally between Ports $C$, and D, wit? Port $C$ lagoing by $90^{\circ}$. The power into Hybrid?, Port A is split in simfiar fashion. Adjustable shorts are connected to Ports $C$ and $D$ of both Hybrids? and 1. If the distances from $C$ and $D$ to the siorts are cqual, the reflectlons from those shorts will be combined in Port $B$ only, therefore. Hybrids? and 4, with thetr assoctated adjustable shorts, function simply

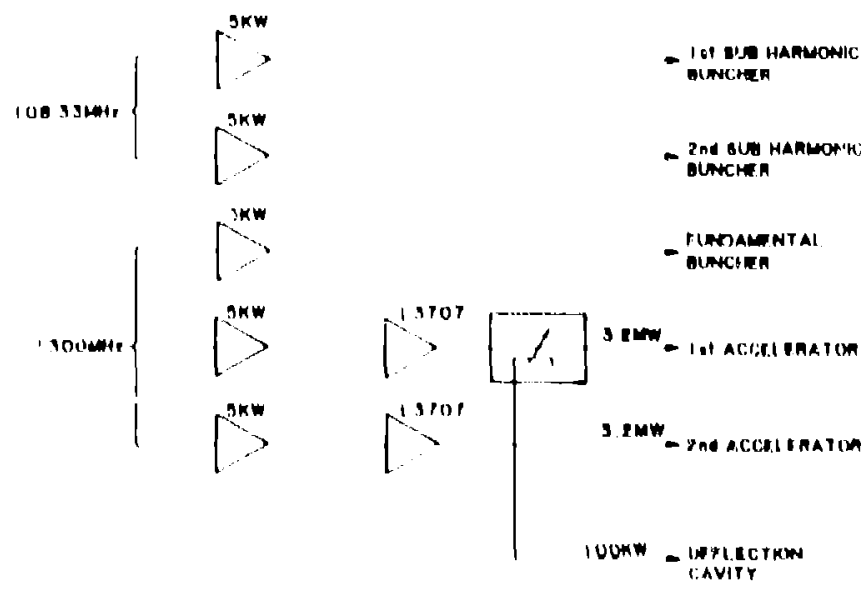

1. li. 1. Hll rf power sources. 
presented somewhat of a dflemma. There were no tubes currently in production, nor had any heen bullt since the 1960 s that would meet the power and frequency requirements. This meant that both the time and expense of a tulin..levelopment program would be necessary to procure: bes. Tube-development time simply was not cons nt with the progrem schedule. Worldwide, the only jwn tubes in existence that possibly could meet the ?quirements were the three surplus Litton L3707 $k$, itrons at White Sands. These tubes had been storeo at White Sands under unknown conditions, then brough to Lus Alamos in the late 1970 s and stored outdo s. With this history it would be impossible to lake a confident prediction regarding the workabllity of the tubes.

Fundamental tests were undertaken on the L3707s. These tests indicated that all triree tubes st 111 had a suitable vacuum, their fllaments had continuity, and the electrode hold-off voltages were encouraging. Following these tests, a successful leam-current test was performed on one of tile tubes. The test was made with $85-\mathrm{kV}$ beam voltage, and $100-\mathrm{A}, 100-\mu \mathrm{s}$ pulses were obtained. Following this last test, we decided to initlate a tube procurement, and to proceed with the program on the assumption that the L3707s would provide the required power, at least until new tube delivery could be made.

The L3707s were designed to operate at $170 \mathrm{kV}$ with a 175-A, 10-11s maximum pulse at a 0.007 duty cycle. The peak rf output power was $10 \mathrm{MW}$. In spite of the successful beam current test on one of the L3707s, there remained a lingering doubt regarding the avallable space charge to iupport the required 100-A 100-us pulses.

The FEL rf test stand was completec in ihe early fall of i982, and testing of the L3707s followed. IIIt imately, the test resulis were completely sut Isfac. tory on all three tubes. Just before testing one of the tubes, we found that it had sustained severe fi-eezing damage, and multiple leaks were present in its cavity water-cooling courses. No encouragement could be found from the repair sections of the demest tc klystron manufacturing companies. Repair at Los Alamos was successfully performed by the klystron repatr section of the I.AMPF accelerator's support aroup. Waveforms typtcal of all three klystrons are shown in Fia. 5.

A developmental contract $h$ is bepn awarded, with dellvery of three new klystrons i xpected in late 1983 ?

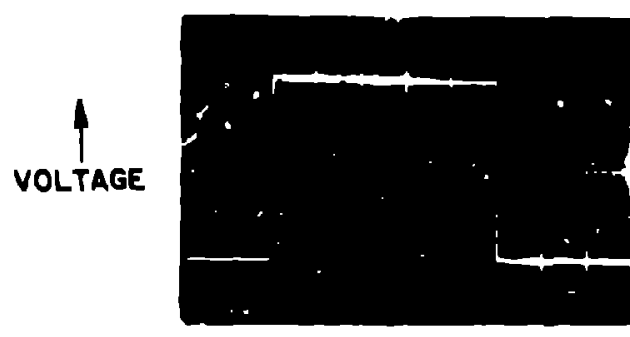

DETECTED

RF ENVELOPE

3.6 MW PEAK

(UNSATURATED)

$20 \mu \mathrm{s} / \mathrm{cm} \rightarrow$

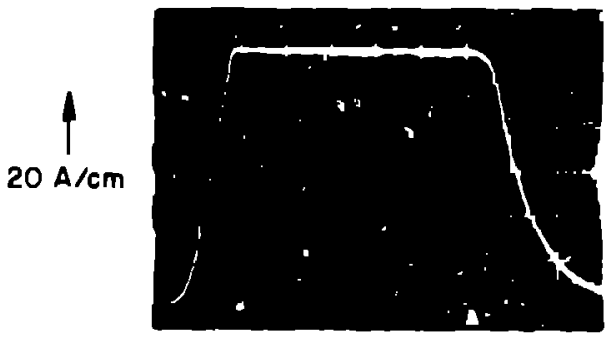

KLYSTRON

CATHODE

CURKENT

$20 \mu \mathrm{s} / \mathrm{cm} \longrightarrow$

Fig. 5. L.ftton $L 3707$ klystron anplifter waveforms. (110-kV beam voltage)

\section{Conclusions}

The klystron uncertaint les that characterized the early part of the program appear to have dissipated; in fact, the klystrens situation has become one of the more promising phases of the FEL Trogram.

The phase and amplitude control systems are in the very early stages of testing; thus, no firin conclusions regardin'l their performance can be made at this titme. Using past expertence on stmilar systems as a predictor, only rout Ine problems are expected. 